\title{
GENETIC RESISTANCE TO DDT IN HORDEUM \\ I. LINKAGE STUDIES IN DIPLOID BARLEY
}

\author{
J. D. HAYES and M. S. RANA \\ Welsh Plant Breeding Station, Aberystwyth
}

Received 4.ï.66

\section{INTRODUCTION}

THE application of DDT to susceptible genotypes of Hordeum causes marked chlorosis, and even death (Hayes, I959, I96o). Hayes (1960), and Wiebe and Hayes ( 1960 ) found that resistance was controlled by a single recessive gene $d d t$. In a series of related analogues of DDT, Wiebe ( 1964 ), and Upshall and Goodwin ( 1964 ) showed that the configuration of the molecule was more important than its chemical composition in conferring phytocidal activity. Upshall and Goodwin (1964) concluded from their investigations that the toxic effect of DDT on a susceptible genotype was due to its gaining access to a functional lipoprotein in the chloroplast by penetrating the covering membrane; in resistant genotypes, DDT is adsorbed on the chloroplast, but presumably, does not penetrate the chloroplast membrane.

The present investigations were designed to locate the $d d t$ locus on one of the seven linkage groups of barley (Hordeum sativum Jess.). The nomenclature adopted for the chromosomes and linkage groups is that described by Ramage, Burnham and Hagberg (196r).

\section{MATERIALS AND METHODS}

Two series of crosses were investigated: the first involved crosses of parents with contrasting genetic markers, and the second a set of crosses between normal parents and a series of translocation stocks.

\section{(i) Genetic markers}

A summary of the information regarding the genetic markers with their linkage group and symbol designation is given in table $\mathrm{I}$.

All the genetic marker stocks were DDT susceptible and were crossed with $\mathrm{Cb}_{7} 6_{3}$ (Proctor), which is DDT resistant. All the genetic markers used were known to be simply inherited and distributed amongst the seven linkage groups.

\section{(ii) Translocation stocks}

The second series of crosses was made between normal cultivars, either the DDT resistant $\mathrm{Cb} 763$ (Proctor) or the susceptible $\mathrm{Cb} 545$ (Rika), and seven homozygous interchange stocks with contrasting DDT reaction. These stocks contain translocations which involve each of the seven chromosomes, and were provided by $\mathrm{Dr} R$. T. Ramage, University of Arizona, Tucson. In an $F_{3}$ population, derived from a cross of a normal genotype with a reciprocal translocation stock, a ratio of I normal : 2 heterozygous translocations: I homozygous translocation is expected. Since normal and 
homozygous translocation stocks both have normal fertility, and genotypes heterozygous for translocations show signs of sterility (referred to as semisterility), a phenotypic ratio of $I$ fertile : I semisterile is expected in the $F_{2}$ generation. After a series of comparisons of parents (o-6 per cent. sterility) and $F_{1}$ hybrids (18-40 per cent. sterility) Io per cent. ovule sterility was selected as the point of differentiation between normal and semisterile individuals.

All the $F_{1}$ hybrids containing the genetic markers and translocations were produced in the glasshouse during the summer and grown under supplementary light in the following winter. $F_{2}$ plants were sown in 3 inch whalehide pots and transplanted to a bird-proof nursery.

\section{TABLE I}

Summary of genetic characters with their linkage groups and gene symbol designations used in linkage tests with the Ddtddt gene

\begin{tabular}{|c|c|c|c|}
\hline $\begin{array}{l}\text { W.P.B.S. } \\
\text { Accession No. } \dagger\end{array}$ & $\begin{array}{l}\text { Linkage group } \\
\text { and chromosome } \\
\text { number }\end{array}$ & Character pair & $\begin{array}{l}\text { Gene } \\
\text { symbols }\end{array}$ \\
\hline $\begin{array}{l}\mathrm{Cb} 822 \\
\mathrm{Cb} 823 \\
\mathrm{Cb} 819, \mathrm{Cb} 820, \mathrm{Cb} 823\end{array}$ & I & $\begin{array}{l}\text { Green vs chlorina seedlings } \\
\text { Normal vs brachytic } \\
\text { Covered us naked caryopsis }\end{array}$ & $\begin{array}{l}F_{0} f_{0} \\
B r b r \\
\mathcal{N} n\end{array}$ \\
\hline $\begin{array}{l}\mathrm{Cb} 868 \\
\mathrm{Cb} 854 \\
\mathrm{Cb} 820, \mathrm{Cb} 822, \mathrm{Cb} 823\end{array}$ & 2 & $\begin{array}{l}\text { Awn vs awnless } \\
\text { Normal vs orange seedlings } \\
\text { Six row vs two row }\end{array}$ & $\begin{array}{l}\text { Lklk } \\
\text { Oror } \\
\text { Vv }\end{array}$ \\
\hline $\begin{array}{l}\mathrm{Cb} 819 \\
\mathrm{Cb} 820 \\
\mathrm{Cb} 86 \mathrm{i}\end{array}$ & 3 & $\begin{array}{l}\text { Green vs white seedlings } \\
\text { Normal vs streaked seedling } \\
\text { Normal vs "Uzu" }\end{array}$ & $\begin{array}{l}A_{n} a_{n} \\
\text { Stst } \\
\text { Uzuz }\end{array}$ \\
\hline $\begin{array}{l}\mathrm{Cb} 822 \\
\mathrm{Cb} 870\end{array}$ & 4 & $\begin{array}{l}\text { Hooded } v s \text { awned } \\
\text { Green vs glossy seedlings- } 2\end{array}$ & $\begin{array}{l}K k \\
G l_{2} g l_{2}\end{array}$ \\
\hline $\begin{array}{l}\mathrm{Cb} 819 \\
\mathrm{Cb} 869\end{array}$ & 5 & $\begin{array}{l}\text { Black vs white lemma and pericarp } \\
\text { Normal vs third outer glume }\end{array}$ & $\begin{array}{l}\text { Bb } \\
\text { Trdird }\end{array}$ \\
\hline $\mathrm{Cb} 86_{5}$ & 6 & Normal vs orange lemma & Oo \\
\hline $\begin{array}{l}\mathrm{Cb} 865 \\
\mathrm{Cb} 867\end{array}$ & 7 & $\begin{array}{l}\text { Rough vs smooth awn } \\
\text { Short } v \text { long basal internode }\end{array}$ & $\begin{array}{l}R r \\
L b l b\end{array}$ \\
\hline
\end{tabular}

† Stocks Cb 81 9-823 supplied by Dr D. W. Robertson, Colorado State University. Stocks Cb $86 \mathrm{r}-87 \mathrm{C}$ supplied by $\mathrm{Dr}$ A. Hagberg, Svalöf, Sweden.

The DDT reaction of $\mathrm{F}_{2}$ phenotypes was obtained by applying a 0.2 per cent. aqueous emulsion of DDT ( $1,1,1,-$ trichloro 2,2 -bis-( $p$-chlorophenyl) ethane) to a single leaf of each plant (Rana, 1965$)$. The genetic constitution of the $F_{2}$ plants was checked by testing $20 \mathrm{~F}_{\mathrm{8}}$ seedlings from each $\mathrm{F}_{\mathrm{a}}$ plant. The most pronounced symptoms of DDT chlorosis on susceptible plants were apparent 2 weeks after application; resistant plants showed no sign of chlorosis.

Tests for goodness of fit of observed to theoretical ratios were made by the use of $\chi^{2}$. The test for heterogeneity was that described by Mather (195I). Where irregularities in the behaviour of individual characters occurred in a dihybrid ratio, the observed frequencies were compared with theoretical frequencies calculated by the use of contingency tables, also outlined by Mather (loc. cit.).

Linkage intensities were calculated from the tables provided by Joachim (1947). These tables enabled the standard error and recombination percentage to be computed from $\mathrm{F}_{\mathbf{2}}$ data, using the product method. 


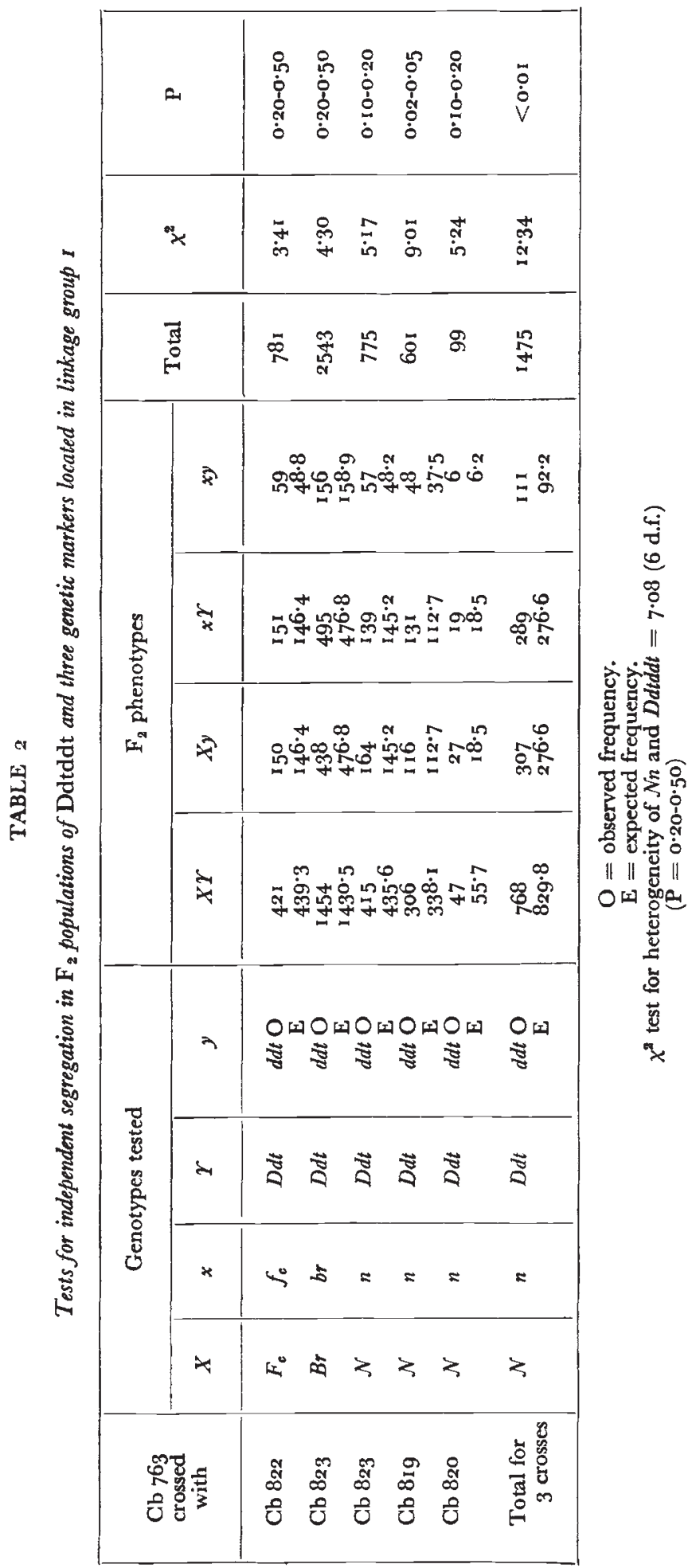




\section{RESULTS}

\section{(i) Tests for linkage with genetic markers}

The results of the linkage tests for each group are presented separately, similar analytical methods were applied throughout, but they are reported in detail only for Group I.

The three characters chlorina $\left(f_{c}\right)$, brachytic $(b r)$ and naked $(n)$ have been located in Group I. The observed ratios, and those expected if the genetic markers and $D d t d d t$ were inherited independently ( $9: 3: 3:$ I ratio), are given in table 2 with the $\chi^{2}$ and probability values.

The $\chi^{2}$ and probability values for linkage of $F_{c} f_{c}$ with $D d t d d t$ $\left(\chi^{2}=3.4 \mathrm{I} ; \mathrm{P}=0.20-0.50\right)$ and $B r b r$ with $D d t d d t\left(\chi^{2}=4.30 ; \mathrm{P}=0.20-\right.$ $0.50)$ indicate that they are independent. The factor $\mathcal{N} n$ was studied in three crosses; in two of these crosses, $\mathrm{Cb} 763 \times \mathrm{Cb} 820$ and $\mathrm{Cb} 763 \times$ $\mathrm{Cb} 823$, the probability for independence was low but not significant $(\mathrm{P}=\mathrm{o} \cdot \mathrm{I0}-0 \cdot 20)$. In the remaining cross, $\mathrm{Cb} 763 \times \mathrm{Cb} 8 \mathrm{I}$, there was a significant deviation $(P=0 \cdot 02-0 \cdot 05)$ of the observed from the expected ratio of $9: 3: 3: 1$. The combined data from all three crosses for $\mathcal{N} n$ also depart significantly $(\mathrm{P}=<0 \cdot 0 \mathrm{r})$ from the expected ratio, the heterogeneity test indicating that the disturbance of the observed segregation from the expected was similar in all three families.

To test the nature of the disturbance from the expected $9: 3: 3:$ I ratio, the deviations of the $D d t d d t$ and $\mathcal{N} n$ factors from an expected $3:$ I ratio, were examined separately. $\chi^{2}$ values for each family and for the combined data are given in table 3 .

The heterogeneity test shows that, averaged over all the crosses, $D d t d d t$ did not segregate according to a $3:$ I ratio and that the three families were consistent in giving an excess of resistant plants. The $\chi^{2}$ value for the $\mathcal{N} n$ factor suggested that there might be some deviation from a 3 : I ratio $(P=0.05-0 \cdot 10)$, but the data of the individual $\chi^{2}$ values for each family indicated that only the progeny from $\mathrm{Cb} 763 \times$ $\mathrm{Cb}$ 8 I9 deviated markedly from a 3: I ratio.

Since the segregation of the $D d t d d t$ factor deviated from a $3:$ I ratio in this series of crosses, the $\chi^{2}$ for independence was calculated in a $2 \times 2$ contingency table. The expected frequencies of the four phenotypic classes, using the observed ratio of 2.5 DDT susceptible: I DDT resistant, and 2.7 covered : I naked, and assuming no linkage, were:

\begin{tabular}{|c|c|c|c|c|}
\hline Frequency & $D d t \mathcal{N}$ & $D d t n$ & $d d t \mathcal{N}$ & $d d t n$ \\
\hline $\begin{array}{l}\text { Expected } \\
\text { Observed }\end{array}$ & $\begin{array}{l}771 \cdot 8 \\
768\end{array}$ & $\begin{array}{l}283_{3} \cdot 8 \\
307\end{array}$ & $\begin{array}{l}306 \cdot 4 \\
289\end{array}$ & $\begin{array}{l}\text { I I } 3.5 \\
\text { I I I }\end{array}$ \\
\hline
\end{tabular}

This provides a $\chi^{2}$ value of 0 . I2 I ( $\mathrm{r}$ d.f.) with a probability value between 0.50-0.95, indicating an absence of any linkage of Ddtddt with $\mathcal{N} n$. A summary of the results from similar tests for independence of $d d t$ with markers in all seven linkage groups is given in table 4. 


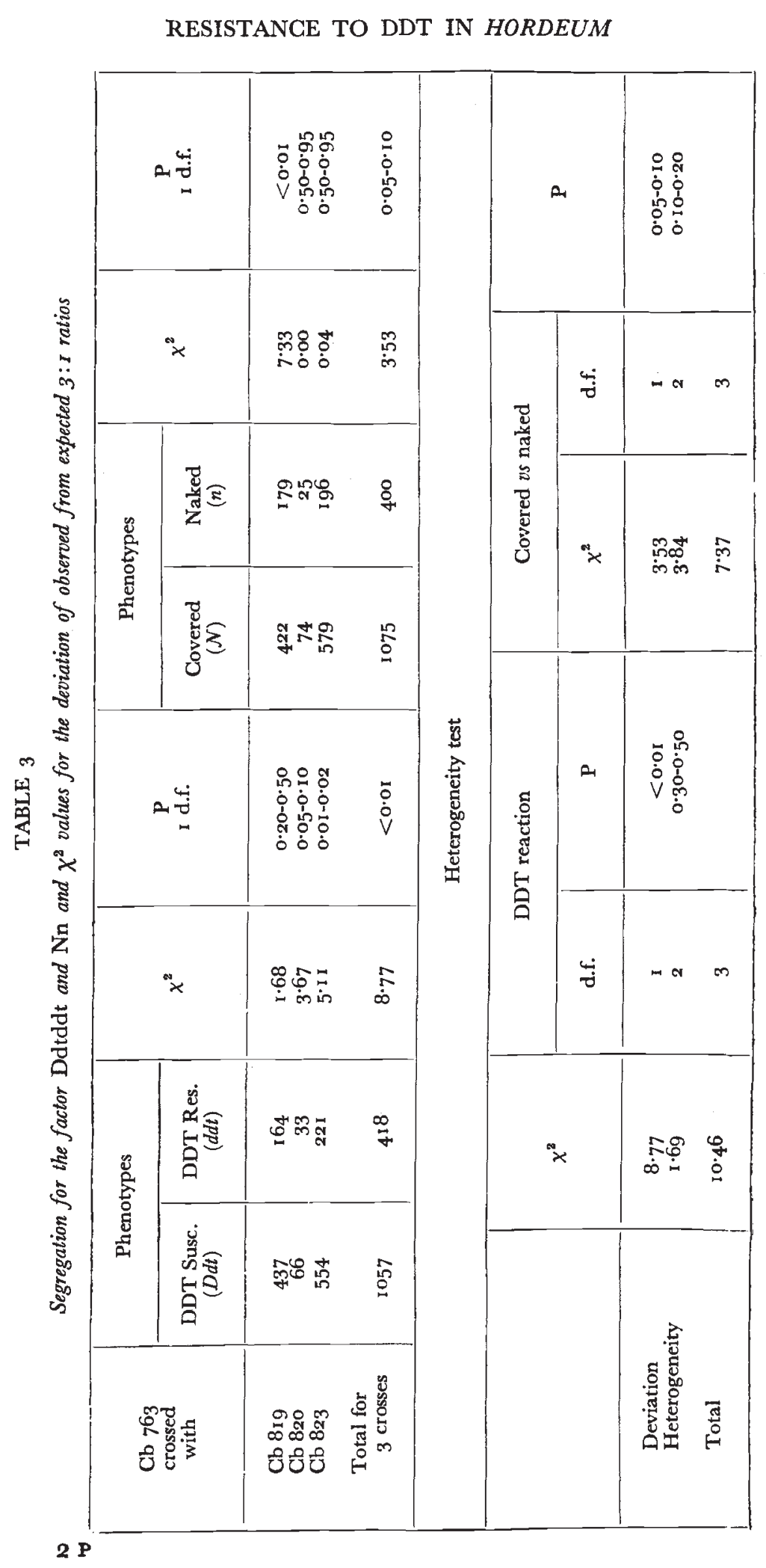




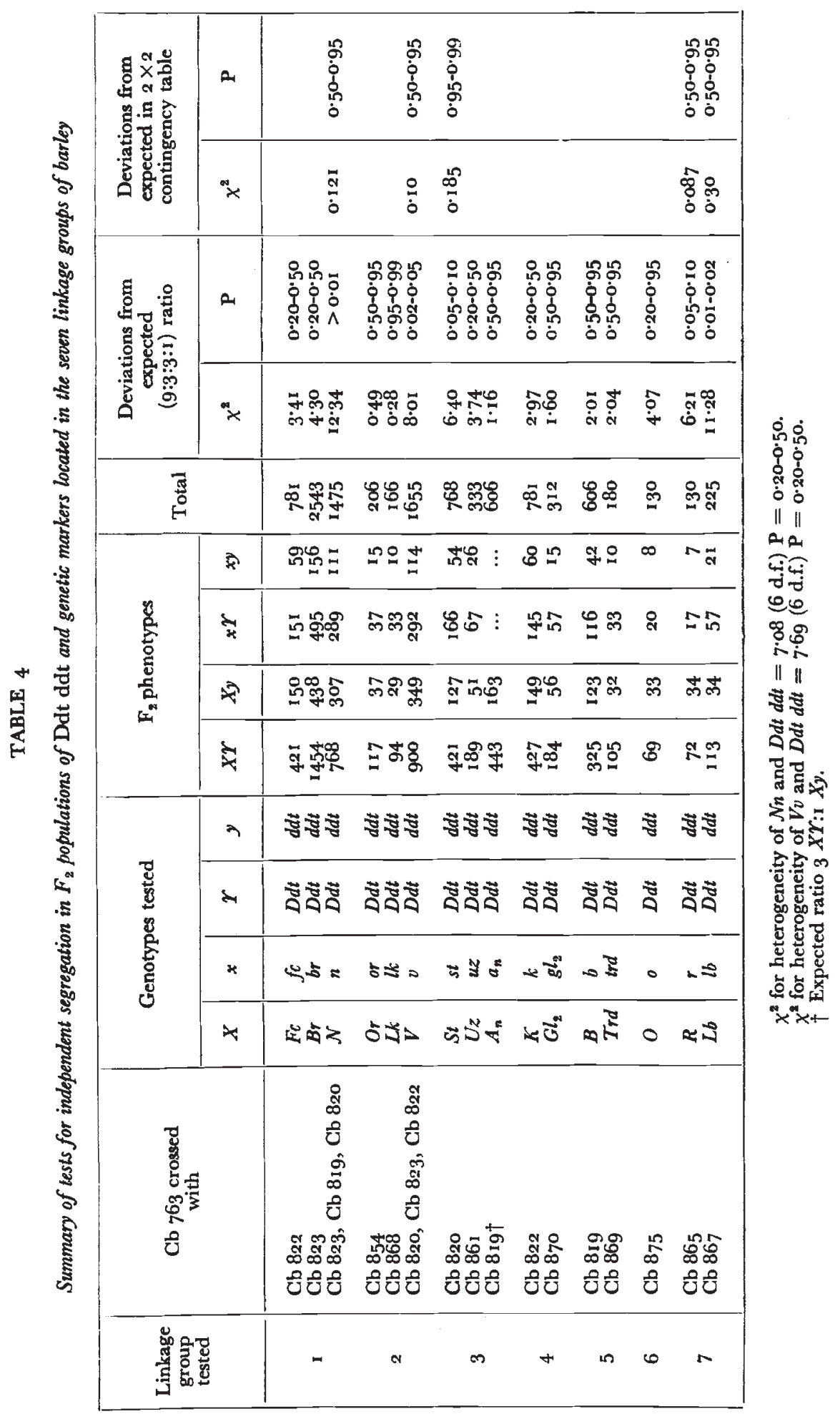


Whenever there was a significant deviation from the expected $9: 3: 3: 1$ ratio, the data were re-tested after adjustment for any deviations of the individual segregation from an expected $3: 1$ ratio. None of the $\chi^{2}$ values calculated on this basis were significant.

The factor $a_{n}$ located in group 3 is a recessive lethal and consequently 25 per cent. of each population is lost. Progeny tests yielded information which enabled the genetic constitution of the $F_{2}$ plants to be inferred:

\begin{tabular}{|c|c|c|c|c|c|c|c|c|c|c|c|}
\hline \multirow{2}{*}{ Cross } & \multicolumn{4}{|c|}{ Genotypes tested } & \multicolumn{4}{|c|}{$\mathrm{F}_{2}$ genotypes (Expected 6:3:2:1) } & \multirow{2}{*}{ Total } & \multirow{2}{*}{$x^{2}$} & \multirow{2}{*}{$\mathbf{P}$} \\
\hline & $X$ & $x$ & $r$ & $y$ & $X \times Y$ & $x x r$ & $X x y$ & $X X y$ & & & \\
\hline $\begin{array}{l}\mathrm{Cb} 819 \times \\
\mathrm{Cb} 763\end{array}$ & $A_{n}$ & $a_{n}$ & $D d t$ & $d d t$ & $\begin{array}{l}\mathrm{O}_{279} \\
\mathrm{E}_{303} \mathbf{3}^{\circ}\end{array}$ & $\begin{array}{l}164 \\
151.5\end{array}$ & $\begin{array}{l}104 \\
101 \cdot 0\end{array}$ & $\begin{array}{c}59 \\
50 \cdot 5\end{array}$ & 606 & $3 \cdot 86$ & $0.20-0.50$ \\
\hline
\end{tabular}

Thus it would appear from the results presented in table 4 that there is a complete lack of association between the $d d t$ locus and any of the markers listed in table $\mathbf{r}$.

\section{(ii) Tests for linkage in translocation stocks}

A summary of the results of $F_{2}$ segregations in crosses between 7 translocation stocks and normal stocks of contrasting DDT reaction is presented in table 5. The $F_{2}$ progeny of three crosses involving $T_{I}-6 a$, $T_{3-7} a$ and $T_{4-5} a$ were grown in both $I_{9} 6_{3}$ and ${ }_{1964}$, since analysis of $F_{3}$ data from these three crosses in 1963 did not fit the expected ratios.

In 1963 progeny involving five translocation stocks failed to fit $(P=0.05)$ the expected ratio of 3 DDT susceptible semisterile: 3 DDT susceptible fertile: I DDT resistant semisterile: I DDT resistant fertile. In four of these five crosses there were deviations from the expected ratios for either $D d t$ segregating or semisterility, but in the fifth cross (involving $T_{3-7 a}$ ) neither character deviated significantly from the expected, and yet there was an overall deviation from the expected 3:3:I : I ratio. The $\chi^{2}$ for independence was obtained by subtracting from the $\chi^{2}$ for joint segregation the two $\chi^{2}$ values for the loci segregating individually. The non-significant $\chi^{2}$ values for linkage of $D d t d d t$ with semisterility indicate that the gene was independent of the points of interchange in six translocations, but for the cross involving $T_{3-7 a}$ the $\chi^{2}$ value $\left({ }^{5} \cdot 34\right)$ was highly significant, indicating that the $D d t$ gene was linked with the points of interchange in this translocation stock. The results from the I 964 tests confirm this point.

The $\chi^{2}$ values from the other two translocations containing chromosomes 3 and $7, T_{2-3} d$ and $T 6-7 b$, did not give any sign of linkage.

(iii) Predictions regarding the position of the $\mathrm{ddt}$ locus

All the available information regarding the genetical and cytological maps of the seven chromosomes of barley has been presented by 


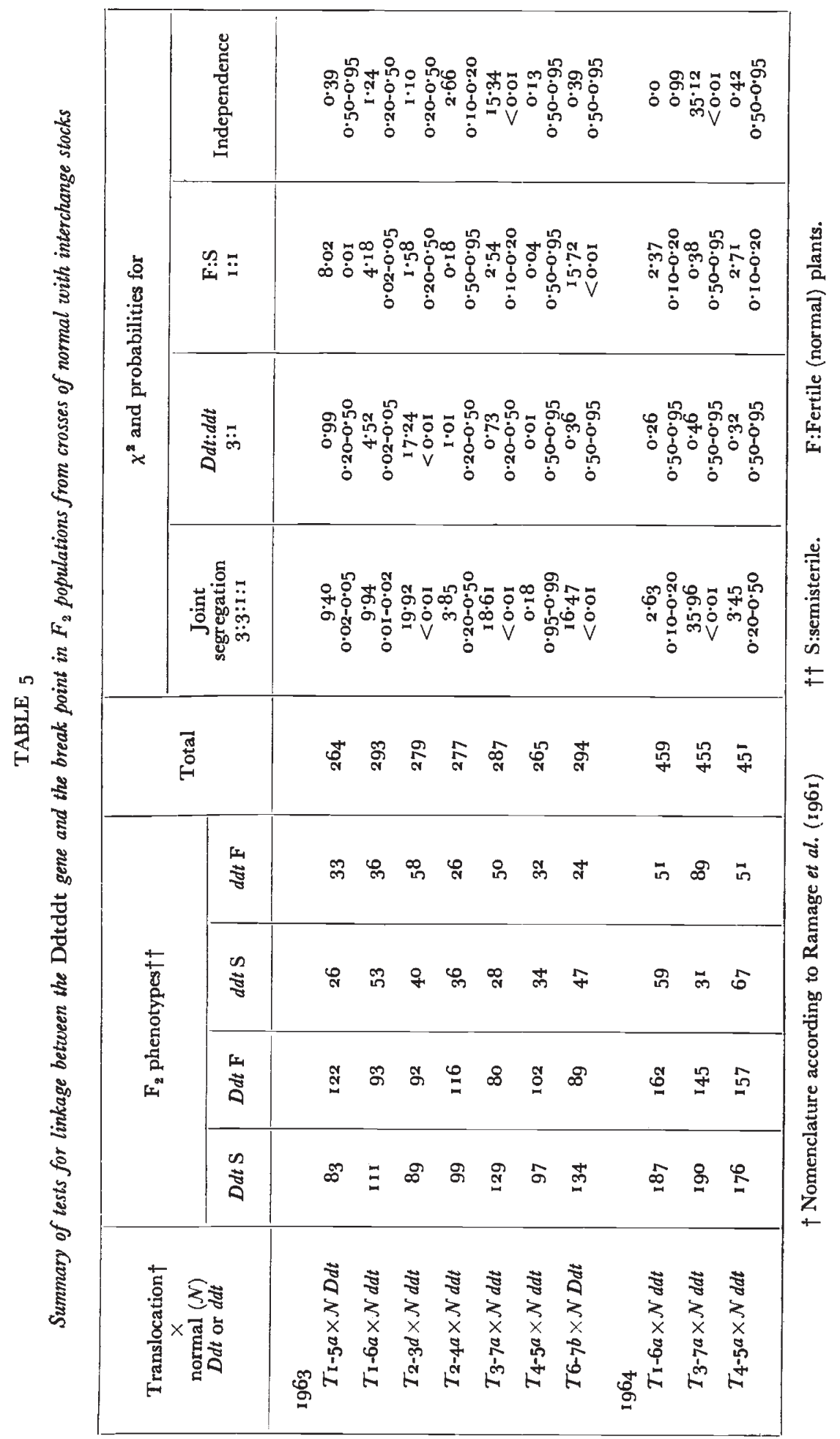


Nilan (1964). From these maps it is clear that the characters used in this investigation are located in each of the 7 chromosomes. $b r, f_{c}$ and $n$ on $\mathrm{r}, L k, v$ and or on $2, a_{n}, u z$, and $s t$ on $3, K$ and $g \mathrm{l}_{2}$ on 4 provide markers in both arms of these chromosomes. But $\operatorname{trd}$ and $B$ provide markers only in the short arm of chromosome 5, while $o$ in chromosome 6 is near the centromere and $R$ and $l b$ are both located in the long arm of chromosome 7 (Robertson et al., 1955). Since there is no evidence of any linkage with the genetic markers investigated, it is highly probable that $d d t$ is not located on chromosome $1,2,3$ or 4 . On the other hand, since any two loci separated by more than 50 crossover units appear in inheritance to be independent, it is clear that if the $d d t$ gene is located in the long arm of chromosome 5 , or in the extremity of either arm of 6 , or the short arm of 7 , it would be possible to miss any association with the characters used in this investigation. However, Hayes (unpublished) has evidence that $d d t$ is independent of the genes responsible for mildew resistance from $H$. spontaneum which are located in the long arm of chromosome 5 (Moseman, 1964).

Data from the crosses involving the seven translocation stocks indicate quite clearly that the $d d t$ locus is linked with the break-point in translocation stock $T_{3-7} a$ (table 5 ). It was not possible to decide from the data of the translocation stocks alone, whether $d d t$ was located on chromosome 3 or 7 , since neither $T_{2-3} d$ nor $T 6-7 b$ showed any sign of linkage with $d d t$. However, by considering the data from the genetic markers and translocations, it was possible to infer that $d d t$ was located in the short arm of chromosome 7.

To test the validity of this inferenc, a further series of translocation stocks with break-points located in cl.romosome 7, was obtained from Dr R. T. Ramage. These were crossed with normal parents having a contrasting DDT reaction; the $\mathrm{F}_{2}$ segregates from these crosses were grown and studied in 1965 . A summary of the linkage data from all crosses involving chromosome 7 is given in table 6 , along with the calculated degree of recombination and standard errors.

Accepting the break positions given by Burnham and Hagberg (1956), Ramage, Burnham and Hagberg (196r), and Ramage and Suneson (196I), the most probable location of $d d t$ in relation to the break-points and the marker genes studied, is illustrated in fig. I.

According to Ramage and Suneson (196I) the break-point of T6-7 $b$ is located in the long arm and $T 6-7 a$ probably in, or near, the centromere. $T_{1-7} a$ is broken in the short arm and, according to our results, $d d t$ is estimated to be 7 crossover units away, but it is not possible to decide whether it is on the proximal or distal side. $T_{4-7} b$ and $T_{\mathrm{I}-7} c$ are broken in the satellite region. Ramage and Suneson (loc. cit.) proposed that the break-point of $\mathcal{T}_{3-7} a$ was located in the short arm of chromosome 7, however, Kasha and Burnham (1965) were of the opinion that the break was in the long arm relatively near the centromere; our results confirm this latter view, since the break of $T 6-7 a$ in or near the centromere has a recombination value of $0.1 \mathrm{I} \pm 0.033$ with 


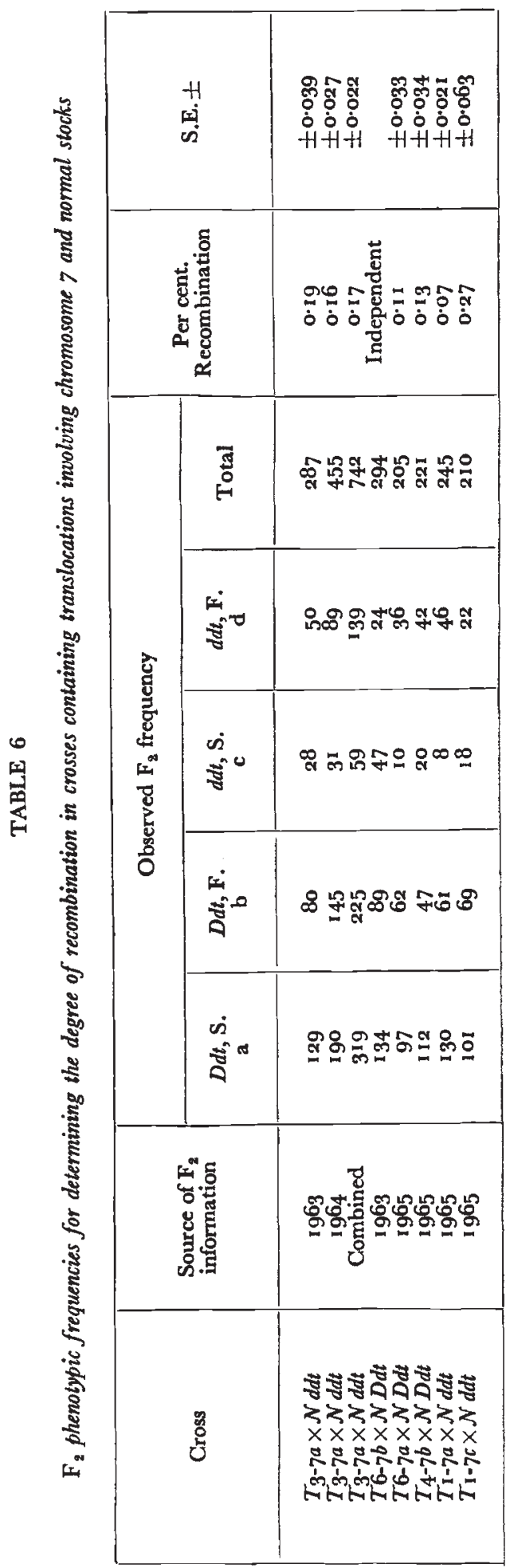


$d d t$, compared with $0 \cdot 17 \pm 0.022$ for the break of $T_{3-7}$. This location of the ddt gene would explain its lack of association with any of the genetic markers tested and with the break of $T 6-7 b$.

\section{CHROMOSOME MAP 7}

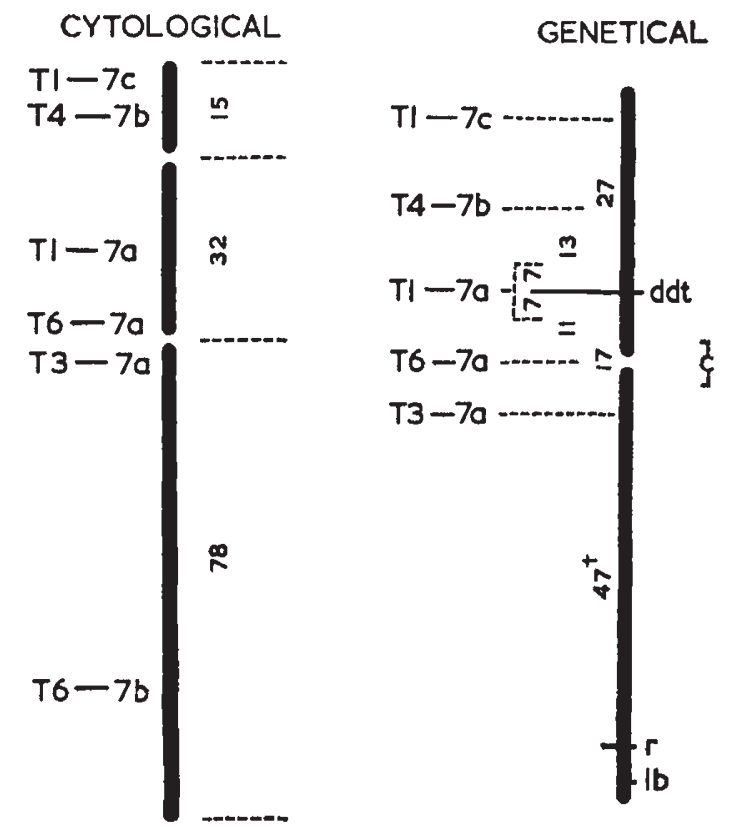

Fic. 1.†-Cytological and genetical maps of chromosome 7 .

$\dagger$ (according to Kramer and Blander, 196r).

\section{DISCUSSION}

Previous studies (Hayes, I959, I96o; Wiebe and Hayes, 1960) have indicated that DDT resistance in barley is controlled by a single recessive gene $d d t$. The results of this investigation confirm this conclusion, but in progeny segregating for covered versus naked $(\mathrm{N} n)$, and two-row versus six-row $(V v)$, there proved to be an excess of DDT resistant genotypes. The $\chi^{2}$ test for homogeneity showed that in each case this bias was consistent in three different crosses, however, there does not appear to be any genetic reason for the excess of resistant genotypes in these particular hybrids.

Some difficulty was experienced in classifying segregates from crosses of normal and translocation stocks since the degree of ovule sterility varied considerably both within and between crosses.

Nilan (1964) indicated that the variation in sterility could be due to the nature of the interchange and the manner of chromosome segregation from the interchange complex. The degree of sterility in an individual plant can be affected by the environment as well as by 
the frequency of crossing over between the centromere and the point of interchange. Ramage ( 1964 ) suggested that the lower-than-expected degree of sterility from the single interchange heterozygotes in barley is probably due to a high frequency of alternate disjunction from the interchange complex, which leads to a reduced recovery of cross-overs in regions included in the interstitial segments i.e. the regions between the centromere and the translocation break-point. Thus the actual distance, as measured by normal genetic markers, is likely to exceed the estimate obtained by using stocks with break-points on the distal side of the $d d t$ locus.

This investigation has demonstrated the value of translocations or chromosomal interchange break-points as genetic markers for mapping those segments of the chromosome which do not, as yet, have any easily identifiable loci. Locating $D d t d d t$ on the short arm of chromosome 7 provides a convenient genetic marker for further studies on the linkage relationships of factors in group 7 , which is not as yet endowed with a large number of easily identified markers.

\section{SUMMARY}

I. Results from numerous hybrid progenies confirmed that resistance to DDT chlorosis in barley was due to a single recessive gene $d d t$.

2. Sixteen well known genetic markers, involving all seven linkage groups, were used in inheritance studies, but they failed to show any linkage with $d d t$.

3. Crosses involving seven translocation stocks which included all seven chromosomes revealed a linkage of $0.17 \pm 0.022$ with the breakpoint in $T_{3-7}$. No association was detected with $d d t$ and the breakpoints in $T_{2-3} d$ and $T 6-7 b$.

4. Further crosses involving four translocation stocks with breakpoints in the short arm of chromosome 7 confirmed that $d d t$ is located in that arm with recombination values of $0.07 \pm 0.021,0.1 \mathrm{I} \pm 0.033$, $0.13 \pm 0.034,0.27 \pm 0.063$, with the break-points in $T_{\mathrm{r}-7 a}, T 6-7 a$, $T_{4-7 b}$ and $T_{I-7 c}$ respectively.

\section{REFERENCES}

BURNHAM, C. R., AND hAGBERG, A. 1956. Cytogenetic notes on chromosomal interchanges in barley. Hereditas, 42, 467-482.

HAYES, J. D. 1959. Varietal resistance to spray damage in barley. Nature, Lond., $183,551-55^{2}$.

HAYES, J. D. 1960. Investigations on the effect of DDT on barley. Rep. Welsh Pl. Breed. Stin, 1959. 76-80.

JOACHIM, GERTRUD STANTON. 1947. The product method of calculating linkage from $\mathrm{F}_{2}$ data involving semi-sterility; and its application to a barley translocation. Genetics, 32, 580-591.

KASHA, K. J., AND BURNHAM, A. 1965. The location of interchange breakpoints in barley. I. Linkage studies and map orientation. Can. 7. Genet. Cytol., 7, 62-77.

KRAMER, H. K., AND BLANDER, B. A. s. Ig6r. Orienting linkage maps on the chromosomes of barley. Crop Sci., r, 339-342. 
MATHER, K. 1951. The measurement of linkage in heredity. 2nd ed. Methuen and Co. Ltd. London.

Moseman, J. G. 1964. Function of the host and pathogen genetic systems in elucidating disease development. Proc. Ist Int. Barley Genetics Symp. Wageningen r963. 215-221.

NILAN, R. A. 1964. The cytology and genetics of barley, 1951-1962. Monographic supplement No. 3, Washington State Univ. Press, 32, pp. 278.

RANA, M. s. 1965. A study of genetic resistance in Hordeum to some chemical compounds. Ph.D. Thesis, Univ. Col. Wales. pp. 138 (unpublished).

RAMAGE, R. T., BURNHAM, C. R., AND HAGBERG, A. 196I. A summary of translocation studies in barley. Crop Sci., I, 277 279.

RAMAGe, R. T., AND suneson, G. A. 1961. Translocation-gene linkages on barley chromosome 7. Crop. Sci., I, 319-320.

RAmage, R. T. 1964. Chromosome aberrations and their use in genetics and breeding-Translocations. Proc. Ist Int. Barley Genetics Symp. Wageningen 1963. 99-I I5.

ROBERTSON, D. W., WIEBE, G. A., AND SHANDS, R. G. I955. A summary of linkage studies in barley: Supplement II, 1947-1953. Agron. 7., 47, 418-425.

UPSHALL, D. G., AND GOODWIN, T. W. 1964. Some biochemical investigations into the susceptibility of barley varieties to DDT. F. Sci. Fd. Agric., 15, 846-855.

WIEBE, G. A., AND HAYES, J. D. 196o. The role of genetics in the use of agricultural chemicals. Agron. F., 52, 685-686.

WIEBE, G. A. 1964. The contribution of DDT and its analogs to the genetics and breeding of barley. Proc. Ist Int. Barley Genetics Symp. Wageningen 1963. 278-281. 